\title{
MUSIIKILLISEN MERKITYKSEN ARTIKULOINTI JA "POPULAARIN" SIJOITTAMINEN MUSIIKINHISTORIAAN
}

Kulttuurielementtien suhteellinen autonomia - luokkataistelu ja artikulaatio • homologian teoriat - musiikillisen merkityksen sopimuksenvaraisuus • kiinnittyneet sivumerkitykset - konjunktuuri ja tilanne - porvarillisen vallankumouksen vaihe $\cdot$ massakulttuurin kausi - popkulttuurin aika - rock kapinana

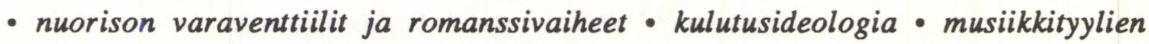
sisäinen vastakohtaisuus - parodiatekniikka - sankari-Elvis ja luopio-Elvis • romanttinen lyyrisyys ja boogittaminen - maneeri-rock

Tässä artikkelissa pohdiskelen sitä miten populaarimusiikin voi sijoittaa merkityksineen musiikinhistoriaan. Esitän alussa yhteenvedonomaisesti teoreettisen mallin, ja yritän sitten soveltaa sită yhteen esimerkkitapaukseen, Elvis Presleyn musiikkiin.

Lähden kahdesta oletuksesta. Ensinnäkin on luultavasti hyödytöntă yrittăă määritellä musiikinlajeja, musiikin funktioita ja musiikin vaikutuksia puhtaasti empiirisin keinoin. "Populaarimusiikin" ymmărtăminen - esimerkiksi kvantitatiivisesti mitattavaksi suosioksi (myyntitilastot) - on vaikeaa tehdä metodologisesti johdonmukaisesti, ja mikä vielă tărkeämpäă, silloin jăhmettyy se mikä todellisuudessa on tulosta elävistă historiallisesti muuttuvista olosuhteista. Toiseksi: vaikka musiikillisia kategorioita pitäisikin käsitellă osana sosiaalisia prosesseja, siită ei kuitenkaan seuraa ettă suureet vastaisivat tăssă suhteessa täydellisesti toisiaan (suureita ovat esim. musiikkityyppi, -kăsite tai käytäntő sekä sosiaalinen ryhmä, sosiaalinen faktori tai sosiaalinen muodostus). Niinpä - lainatakseni jälleen arkiajattelua - käsitys, että populaarimusiikki "todella" on vain aitoa proletaarista itseilmaisua, on yhtä harhaanjohtava kuin adornolainen käsityskin, ettă populaarimusiikki on osa eriytymätöntä vapaa-ajan viihdykkeiden mattoa, jota monopolikapitalistinen "kulttuuriteollisuus" tyrkyttää vastustuskyvyttömille joukoille.

Vastoin edellistă musiikilliset kategoriat olisi syytă määritellä topografisesti (vaikka topografia Franco Fabbrin mukaan onkin moniulotteinen asia, ks. Fabbri 
1982). Stuart Hallin mukaan taas "populaarikulttuuri ei ole 'puhtaassa' mielessä kansanjoukkojen vastarinnan perinnettä ... eikă se ole sitä sen ylärakenteen muotonakaan. Se on perusta jolla transformaatiot toimivat" (Hall 1981, 228). Avaintermejä ovat tässä "prosessi", "suhde", "transformaatio", "ristiriita". Termi populaarimusiikki pyrkii erityisesti kajoamaan siihen ristiriidan tilaan tai alueeseen, joka muodostuu vastakohtien ylhäältäohjattu ja autenttinen, yläluokka ja rahvas, hallitseva ja alisteinen, silloin ja nyt, heidän ja meidän jne. vălille - ja jäsentäă siă tietyillă tavoilla. Tăllă alueella liikkuvat suhteet saavat eri muotoja eri yhteiskunnissa, ja ne täytyy analysoida omassa kontekstissaan. Ja koska ne ovat myös toimivia (eikä kenttä ole koskaan pysähtyneessă tilassa), populaarimusiikin mahdolliset merkitykset tăytyy paikantaa myös historiallisesti.

Toinen tapa lähestyă tătă aluetta on käsittäă kulttuuriset tavat ja käytănnơt suhteellisen autonomisiksi. Tässä on hyödyllistă lainata Gramscin käsitystä, ettă suhteet yhtäältă itse kulttuurin, tietoisuuden, ideoiden ja kokemusten sekă toisaalta taloudellisesti määräytyvien seikkojen kuten luokka-aseman vălillă ovat aina ongelmallisia, vajavaisia ja ideologisen toiminnan ja taistelun kohde. Tämå liittyy Gramscin yleiseen oletukseen taloudellisten voimien ja pintarakenteen elementtien välisestä suhteesta. Kun hän kannattaa edellisen hallitsevaa asemaa, hän painottaa jälkimmäisen suhteellista autonomiaa: pintarakenteen elementeillă on omat olemassaolon muotonsa, oma painovoimansa, oma aikakäsityksensă, ja nämä ovat senlaatuisia että meidän on puhuttava "tarpeellisesta vastavuoroisuudesta" taloudellis-sosiaalisen ja kulttuuris-ideologisen tason vălillä. Kulttuuriset suhteet ja kulttuurinmuutos eivăt năin ole ennaltamăărăttyjă, vaan pikemminkin tulosta neuvonpidosta, ohjailusta, vastustuksesta, muodonmuutoksesta jne. Luokkayhteiskunnissa tämä prosessi ilmeisesti vălittyy etupăăssă joskaan ei yksinomaan - luokkasuhteiden ja luokkaristiriitojen avulla. Niinpă eri kulttuurimuotoja ja -käytăntőjä ei voi mekaanisesti tai edes paradigmaattisesti yhdistää tiettyihin luokkiin, ja sama koskee myős yksittäisen muodon tai käytännőn erilaisia tulkintoja, arvostuksia ja hyödyntämistä. Stuart Hallin mukaan "ei ole erillisiă 'kulttuureja' [- ei porvarillista iskelmää, ei 'proletaarista' työväenlaulua, ei 'pikkuporvariston' operettia, tai 'tyővăenluokan' rockia -] ... jotka liittyisivăt historiallisesti muuttumattomina tiettyihin 'kokonaisiin' luokkiin - vaikkakin on olemassa selvästi erillisiä ja vaihtuvia luokkakulttuurisia muodostumia" (Hall 1981, 238). "'Kulttuurisen' alue ... ei ole luokkakantaisuuden homogeeninen ilmaus, vaan se muodostuu erillisistä ja eriytyneistä käytănnőistă, muotoutumisen ja neuvottelun tuloksena" (Mercer 1978 , 27). Paras lăhestymistapa on sellainen, joka "käsittelee kulttuurin muotojen ja toimintojen alaa jatkuvasti muuttuvana kenttănă ... tarkastelee suhteita jotka jatkuvasti jäsentävăt tätä kenttää hallitseviksi ja alisteisiksi muodostumuksi ... sekä tapahtumasarjoja, joilla nämä hallinta- ja alistussuhteet artikuloidaan" (Hall 1981, 235).

Jos musiikin elementit, muodot ja lajit eivät ole tiettyjen luokkien omaisuutta, jos niiden olemassaoloa ei selitä yksittäinen ilmaisutarve, vaan se on monien tekijöiden summa, kuinka ne sitten omaksutaan tiettyjen luokkien tai luokkaryhmittymien käyttöön? Hall käyttää termiä artikuloida, ja Chantal Mouffe (1979) sekä eräät muut ovat Gramscia lainaten puhuneet "artikulaation periaatteesta". Tämä sisältää ajatuksen, että vaikkakin kulttuurin elementit eivät 
suoraan, aina ja yksinomaan ole sidoksissa tiettyihin taloudellisesti määräytyviin tekijöihin kuten luokka-asemaan, ne lopulta kuitenkin määräytyvät näiden mukaan, niihin sidoksissa olevien artikuloivien periaatteiden (arvomaailmojen) välityksellä. Nämä periaatteet toimivat yhdistämällă olemassaolevia elementtejä uusiin kaavoihin tai liittämällä niihin uusia sivumerkityksiă. Tulos - tai pikemmin toivottu tulos, sillä artikulointiprosessista voidaan aina olla montaa mieltä - on tietty rakenne, jota Gramsci kutsuu "kansallisesti populaariksi": se on saatavilla ja pelissä olevien kulttuuris-ideologisten elementtien repertoaari, joka pyrkii joko muodostamaan tai kumoamaan hegemonian.

Artikulaation teoria myöntää kulttuuristen kenttien monimutkaisuuden. Se jättää pintarakenteen elementeille (esim. musiikilliset rakenteet) suhteellisen autonomian; toisaalta se väittää, että em. yhdistelykaavat on varsinaisesti rakennettu välittämään yhteiskunnallis-taloudellisen muodostuman syviä, objektiivisia malleja ja että välittyminen tapahtuu taisteluna: luokat taistelevat artikuloidakseen yhteen kulttuurisen repertoaarin ainesosia siten, että ne vastaavat niitä periaatteita ja arvoja, jotka määräytyvät luokka-aseman ja luokkaintressien mukaisesti vallitsevassa tuotantomuodossa. Tämä teoria näyttää minusta parhaalta paljastamaan suhteet musiikillisten muotojen ja käytäntőjen sekä luokkaintressien ja sosiaalisen rakenteen välillä. Se on hienosyisempi kuin vaikkapa homologian teoriat, joita esimerkiksi jotkut etnomusikologit ja brittiläinen alakulttuuriteoria ovat tuoneet esille ja joiden mukaan kulttuuria muodostavien eri elementtien sekä tietoisuuden ja tietyn sosiaalisen aseman välillä on olemassa rakenteellisia "resonansseja" tai homologioita (ks. Chambers 1982, 31-32; Willis 1978, 189-203; Hebdige 1979, 133- ). Haluaisin silti käyttää myös homologian käsitettä pienin varauksin. Näyttää nimittäin siltä että jotkut merkityksiä kantavat rakenteet ilmaisevat toisia rakenteita helpommin yhden ryhmän intressejä; vastaavasti ne ilmaisevat helpommin yhden ryhmän intressejä kuin toisen. Tämä johtuu siitä että - seuraten Willisin luonnehdintaa aineellisten ja ideologisten rakenteiden "objektiivisista mahdollisuuksista" (ja rajoituksista) - on helpompaa löytää yhtymäkohtia ja rinnakkaisuuksia pikemmin niiden kuin joidenkin muiden välillä. Ajatelkaamme esimerkiksi János Márothyn tekemää eroa niinsanottujen "kollektiivis-varioivien" menetelmien ja symmetristen soololaulun muotojen välillä; edellisen hän liittää pääasiassa proletaariseen musiikinharjoitukseen, kun taas jälkimmäinen on ollut tyypillistä porvarilliselle musiikkikulttuurille keskiajalta lähtien (ks. Márothy 1974). Olisi erehdys katsoa näiden kahden kategorian syntyneen luokkatarpeista. Mutta on selvää, että - objektiivisista rakenteellisista syistä johtuen - tiettynä pitkänä historiallisena kautena porvariston oli helpompi hyödyntää mielekkäästi jälkimmäistä ja työväenluokan ensimmäistä kuin päinvastoin. Vastaavasti työväestön musiikinharjoituksen oli vaikeaa soveltaa porvariston soololaulujen elementtejä muuten kuin sopeutumalla hallitsevan musiikkikulttuurin normeihin tai käsittelemällä niitä parodisesti tai muuntelemalla muulla tavoin.

Kuitenkin vaikka musiikin merkitykset ja tottumukset ovatkin melko sopimuksenvaraisia - eivätkä "luonnollisia" tai ihmisluonnon tai luokan ilmaisutarpeiden mukaan määräytyneitä - sen jälkeen kun tiettyjä musiikkielementtejä on yhdistelty tietyillä tavoilla, ja kun ne ovat saaneet tiettyjä sivumerkityksiä, näitä voi olla vaikea muuttaa. Olisi vaikeaa esimerkiksi siirtää 
Marseljeesi pois sen ympărille kasautuneiden merkitysten piiristă - sama pătee muihinkin vastaavantyyppisiin kappaleisiin - jotka merkitykset juontuvat Ranskan porvarillisen vallankumouksen historiasta. Vastaavasti ei ole helppo kajota sentyyppisen "kansanlaulun" sivumerkityksiin, jotka porvarillinen romantiikka loi (tunneperäisen) "yhteisön", orgaanisen sosiaalisen tasapainon merkiksi; 1900-luvun Tin Pan Alleyn romanttis-lyyrinen laulutyyli on tiukasti kiinni roolissaan, ja se esittăă sukupuolten văliset suhteet normeina, joiden pohjana on porvarillinen parisuhde-stereotypia, vaikkakin sită on aika ajoin yritetty siirtăă uusiin ja uudenlaisia merkityksiă sisăltăviin kaavoihin. Niinpä teoria artikulaatiosta ei merkitse ettă musiikillinen kenttă on moniarvoinen ja avoin kaikille. Se ei ole ennaltamääräämätön vaan liikamäärätty, ja hallitsevan luokan intressit ovat sosiaalisessa asetelmassa etunenăssä asettamassa ennakkomääräyksiä jotka pyrkivät aina saattamaan voimaan vakiintuneen muodon. Kuten Gramsci osoittaa, "porvaristo on jatkuvassa liiketilassaan kuin elävä organismi, joka voi vetăă piiriinsă koko yhteiskunnan ja sulauttaa sen omalle kulttuuriselle ja taloudelliselle tasolleen" (Gramsci 1971, 260). Tämä mahdollinen universalisointipaine käy yhdeksi tärkeimmistä elementeistä musiikinhistoriassa viimeisten kahdensadan vuoden aikana. Niinpä Gramscin käsityksen - luokkaliittojen jatkuva rakentaminen, johon liittyy artikuloiva ulottuvuus kulttuurisella alueella - takana on piilevä kahtiajako, ja se jäsentyy "hegemonisen" ja "alistetun" vyőhykkeen ympärille (kummankin termin sisältő ja koko alue on kummankin vyöhykkeen säătelemă, ja se on kulttuurisen kuin myös taloudellisen taistelun nimenomaisena kohteena).

On vielä syytä lisätä ettei kumpikaan näistă vyöhykkeistä määräydy vain luokka-aseman perusteella - niin keskeistă kuin se onkin - vaan myös muiden sosiaalisten tekijöiden, varsinkin iăn, sukupuolen, etnisiteetin ja kansallisuuden mukaan. Kukin näistä voi toimia jonkun toisen tai kaikkien muiden välittäjänä. Kun piilevä kahtiajako sosiaalisessa muodostuksessa on yhteiskunnan kehittyessä kohti monopolikapitalismia ja sen aikana tullut yhä jyrkemmäksi, on syntynyt tilaa paikallisille, usein lyhytikäisille "konstellaatioille" (alakulttuureille); näitä alakulttuureja muodostuu eri sosiaalisten faktorien leikkauskohtiin. Niinpä kun nuori Elvis Presley käytti hyväkseen erilaisia, jo olemassaolevia musiikillisia, lyyrisiä ja esityksellisiä elementtejä, voidaan väittäă että hănen vaikutuksensa johtui tavasta, jolla hän artikuloi niitä uudelleen uudeksi kaavaksi; tämä kaava asettui tiettyjen mielikuvien leikkaus- ja vălikohtaan - mielikuvia ovat mm. luokka (proletaarinen), etnisiteetti (musta tai köyhä valkoinen), ikä ("nuoruus"), sukupuoli (mies) ja kansallisuus (Yhdysvaltain etelävaltiot). Artikuloiva periaate vaikuttaa ratkaisevasti siihen, millainen on tämän musiikin sosiaalinen merkitys yleisölleen; sen määrittely täytyy yhdistää uuteen käsitykseen vapaa-ajasta, kehosta, sukupuolten välisistä suhteista ja kapitalistisesta kulutuksesta, jotka vuorostaan ovat sidoksissa tämän yleisön objektiivisesti uudenlaiseen yhteiskunnallis-taloudelliseen asemaan sodanjälkeisessä kapitalistisessa yhteiskunnassa. Tästä syystä esimerkiksi Elviksen tyylin romanttis-lyyriset elementit saattoivat saada uusia merkityksiä; nämä välittyivät sellaisina kuin välittyivät country and westernin ja mustan musiikin aiemmista kaupallisista muodoista, Etelän työväestön "alaluokkaisesta" näkemyksestä amerikkalaiseen unelmaan ja uudesta vapauskäsityksestä nuorison vapaa-ajan käyttäytymisessä. 
Tietenkin senlaatuisen "konstellaation" vaikutukset näkyvät kuulijoiden sosiaalisessa tilanteessa. Nuoren Elviksen "kansallisuustekijällä" oli melko erilainen merkitys 50-luvun puolivälin englantilaisille nuorille - ja taas epäilemättä erilainen italialaisille nuorille; se välittyi sen kuvan kautta, joka Yhdysvaltojen eteläosista oli noissa kansallisissa perinteissä ja vieläkin laajemmin, se välittyi noissa perinteissä vallitsevan melko erilaisen sukupuoli-, sukupolvi- ja luokkarakenteen ohjaamana. (Tämä tarkoittaa ainoastaan, että artikulointiprosessien toimiessa tuotanto ja kulutus liittyvät erottamattomasti yhteen - tämä on tärkeä seikka joka vaatisi paljon laajempaa pohdiskelua kuin mihin tässä on tilaa). Vastaavasti Elviksen nuoruuskauden (ja yleensäkin rockin alkuaikojen) vaikutukset muuttuvat ajan mittaan, kun artikulointitekijät vaihtuvat. Joskus tämä vaikuttaa musiikin tuottamiseen, ja joka tapauksessa se vaikuttaa aina musiikin vastaanottotapoihin. Niinpä varhaiskauden Elviksen luokkaorientaatio vaihtui, kun hänen musiikkinsa artikuloitui musiikkiteollisuuden hallitsevien elementtien mukaiseksi, ja samanaikaisesti hänen sukupolvelleen ominainen terävyys pehmeni. Myöhemmin vanhat kappaleet tulevat uudelleen muotiin ja ne saavat uusia merkityksiä, jotka ovat lähempänä alkuperäisiä mutta joita taistelut rock and rollista ja sen merkityksistä väistämättä muuntavat. Elvis - tiettynä musiikillisena kasautumana - ei siten koskaan kuulunut kenellekään erityisesti; hän - tai se - oli kohde, jonka omistuksesta taisteltiin.

Tämä on esimerkki tavasta, jolla musiikillista kenttää rajaavat synkroniset ja diakroniset akselit sekoittuvat analyysiin. On yhtä tärkeää paljastaa keskeiset liittymäkohdat - leikkautumalla läpi suhteiden joita jokaisena aikana sosiaaliskulttuurisessa muodostumassa on, ja tunnistamalla niiden muuttuva strukturointi, - jotka synnyttävät joukon transmutaatioita, jatkuvuuksia ja katkokohtia. Gramsci näkee tämän eron kahtena rakennetyyppinä tai tasona: "tilanteena" ja "konjunktuurina". Tilanne viittaa sosiaalisen muodostuksen syvimpiin, orgaanisiin rakenteisiin; liike siinä on perustavaa laatua olevaa ja suhteellisen pysyvää, tulosta kriisistä. Konjunktuuri viittaa välittömämpiin, lyhytaikaisiin luonteenpiirteisiin, jotka liittyvät orgaanisiin rakenteisiin, mutta jotka muuttuvat heti nopeammin ja vähemmän merkittävästi, kun tilanteen konfliktissa olevat voimat taistelevat selviytyäkseen ristiriidoista. Gramsci näkee näiden kahden tason olevan dialektisessa suhteessa keskenään. Mutta samalla on selvää, että toisina kausina sattuu tilanteen murroksia kun taas näiden välillä tilanteissa on suhteellisen vakaita kausia, kun päivittäinen konjunktuuriliike omaksuu selvemmän aseman historian kentässä. (ks. Gramsci 1971, 175-185). Näin eritellen muutosten tärkeys "perustassa" säilyy - se on tilannetasolla, jolla homologian aiemmin esityssä merkityksessä voidaan ajatella toimivan - kun taas ylärakenteen elementeille varmistetaan suurempi suhteellinen itsenäisyys konjunktuurin tasolla, sillä nämä elementit voivat muuttua eri nopeuksilla, eri tavoilla.

Kun hahmotellaan musiikinhistoriaa viimeisten kahden sadan vuoden aikana, voidaan tilannetasolla uskoakseni tunnistaa kolme murroksen "vaihetta". Nämä näyttävät löytyvän kaikista kehittyneistä länsimaista, vaikka eroavat ajallisesti toisistaan. Juuri näihin ajanjaksoihin tutkimuksen kannattaisi ehkä keskittyä tietämyksen nykyvaiheessa, koska ne paljastavat selvimmin musiikillisideologisten kenttien muodostuksen. 
Ensimmäinen näistä on "porvarillisen vallankumouksen vaihe", jota leimaavat monimutkainen ja avoin taistelu kulttuurin kenttien välillä, markkinakoneiston leviäminen melkein kaikkiin musiikillisiin toimiin sekä uusien musiikkityyppien kehitys ja lopullinen ylivalta, mikä oli yhteydessä uuden hallitsevan luokan syntyyn. (Tämä kehitys pyrkii - yleisesti ottaen siirtymään sankarillisesta, edistyksellisestä painotuksesta kohti jäykistävää, tukahduttava konservatismia.)

Tämän kauden tavanomainen jaottelu musiikinhistoriassa joko tiukasti klassiseen ja romanttiseen jaksoon tai suurmiesten elämänkertoihin kätkee alleen mutkikkaan vuorovaikutusten verkon - tähän liittyvät konserttimusiikki, keskiluokan kotimusiikki, näyttămömusiikki, tanssi, kuorolaululiike, poliittinen ja protestilaulu, työväenluokan arkkiveisut ja katulaulut; nämä olivat aktiivisen taistelun kohde kun vanhoja ja uusia elementtejä artikuloitiin erilaisiksi kaavoiksi ja merkityksiksi. Englannissa tämä jakso on monivaiheinen sen pitkän ja kuohuvan kauden aikana, joka kestäă 1700-luvun keskiväliltă 1840-luvulle. Useimmissa Länsi-Euroopan maissa se näyttäisi alkaneen hieman myöhemmin mutta vakiintuneen noihin samoihin aikoihin, vuoden 1848 vallankumouksen jälkeen.

Toinen vaihe on mielestäni "massakulttuurin kausi", joka ulottuu 1800-luvun lopulta noin vuoteen 1930. Sille ovat luonteenomaisia monopolikapitalismin kehittyminen, tavat joita on kutsuttu sosiaaliseksi imperialismiksi sekä luokkataistelun yksinkertaistuminen muodoiksi, jotka (olivat ne miten vaihtelevia tahansa), voidaan sijoittaa Stuart Hallin yleiseen kahtiajakoon "valtaryhmittymä vastaan rahvaansyntyiset" (Hall 1981, 238-9). Kansallinen tausta pysyy tärkeänä mutta vain yhtenä jännitysnapana, jota tasapainottaa kulttuurin lisääntyvä kansainvälistyminen (tämä liittyy erityisesti Yhdysvaltain kulttuurihegemomian syntyyn). Tämä näkyy sekä musiikin sisällössä - ragtimen, Tin Pan Alley -laulujen, uusien tanssimuotojen jne. vaikutuksessa - että uusissa joukkotuotannon, levityksen ja julkisuuden menetelmissä: lyhyesti sanottuna pyrkimyksessä "yhdensuuntaiseen kommunikaatioon" homogeenisilla markkinoilla. Tämä ei kuitenkaan saisi johtaa aliarvioimaan ristiriitatilanteita, joita liittyy uuden systeemin perustamiseen; systeemi sijaitsee nyt nähtävästi melkein kokonaaan kulutuksen puolella (koska tuotantovälineet ovat yhä enemmän suurten teollisuuskonsernien käsissä). Kuten usein on huomautettu aina Walter Benjaminista alkaen (ks. esim. Wicke 1982), itse "joukkojen synty" (kvalitatiivisesti uutena tekijänă musiikillisessa prosessissa) tarjoaa mahdollisuuden uusille poliittisille ulottuvuuksille musiikillisen merkityksen kohdalla; sitäpaitsi monilla uusista musiikillisista elementeistä, jotka omaksuttiin tällöin Yhdysvaltain mustien keskuudesta, oli voimavaroja vallitsevien musiikkinormien kaatamiseen ja uusien artikulaatioyhdistelmien muodostamiseen - käyttămällä hyväksi esimerkiksi "kollektiivisia variointikeinoja", jotka olivat peräisin monista vanhemmista työväenperinteistä. 1920-luvun loppupuolella ja 30-luvulla sosiaalinen kriisi kuitenkin tasoittui suhteellisesti (fasismin nousun tai toisaalla vapaamielisempien taantumushallintojen synnyn myötä), ja rinnan tämän kanssa omaksuttiin laajalti afroamerikkalaisia -ismejă synteesiksi, jota hallitsevat vankat yläluokkaiset musiikkiperinteet ja jossa niiden merkityksiä artikuloidaan kulutuseskapismin ideologian mukaisesti (pehmeä-ääniset iskelmälaulajat, isot 
tanssiorkesterit jne.). Vastaavaa dialektiikkaa voidaan havaita yläluokan konserttielămăssă vuosien 1890 ja 1930 vălisenă aikana, vaikkakin tăssă se toimii myös sävellystekniikan tuotannollisella alalla, joka (kuten Adorno osoittaa), pyrkii tekemään täyskäännöksen joko schönbergiläiseen "kriittiseen eristäytymiseen" tai stravinskylaiseen mekanismiin ja "sosiaaliseen juhlintaan". Tässäkin kamppailu tyyntyi vanhoilliseen uusklassiseen ylivaltaan, joka oli tyypillistä kolmi- ja nelikymmenluvuille. Kuten myös kansanomaisten musiikinlajien kohdalla, yksikään yksittäinen musiikillisen tekniikan elementti täydellinen kromatiikka, additiiviset rytmit, ostinaatokaavat jne. - ei omannut kiinteää merkitystä tai sitä ei voitu liittää mihinkăän nimenomaisiin sosiaalisiin tekniikkoihin. Pikemminkin ne artikuloitiin erilaisiin musiikillisiin sovituksiin sopiviksi ja vastaamaan erilaisten sosiaalisten intressiryhmien makua. Weill ja Eisler sekä Bartók ja Janacek osoittivat ettă monet samoista tekniikoista voitaisiin artikuloida toisenlaisiin makuihin - yleisesti ottaen sosiaalisiin ja vapaamielis-edistyksellisin, tăssă järjestyksessă.

Kolmas ajankohta alkaa joskus toisen maailmansodan jälkeen - mită silmiinpistävimmin samanaikaisesti rockin kanssa - ja sită voidaan ehkă nimittăă "popkulttuurin ajaksi". Tällä kaudella dikotominen malli, joka sopii kuvaamaan melko hyvin "massakulttuurin" tilannetta, näyttäisi murtuvan tai se menee ainakin selvästi särölle; tähän on syynă eräiden nopeasti muuttuvien, usein näennäisesti yhteiskunnanvastaisten tyylien ja alakulttuurien kehittyminen. Samanaikaisesti teknologiset muutokset ("massakulttuurille" tyypilliset elektroniset järjestelmät syrjăyttävät sähkömekaaniset kăyttötavat, aivan samoin kuin sähkömekaaniset tuotanto- ja jakelutavat olivat syrjäyttäneet aiemman porvarillisen ajanjakson puhtaasti mekaaniset tavat, joita nuottipainatus edusti) luovat mahdollisuuksia uusille tuotantotavoille - magneettinauha korvaa nuotit, "kolmen soinnun" sähkökitara asettaa ammattilaisten soittotaidon kyseenalaiseksi. Myös tuotantosuhteissa esiintyy vastaavia muutoksia; năistă tărkein on nuorison, erityisesti tyőväenluokkaisten nuorten harrastelijoiden ensimmăinen merkittăvă aluevaltaus musiikkituotannon resursseihin, ja tăhăn liittyi uusien markkinoiden, nuorisomarkkinoiden muodostuminen, jonka kuluttajakunta on rakenteellisesti vähemmän sidoksissa vallitseviin luokkarooleihin kuin vanhemmat ikäpolvet.

Tämä ryhmä, jolla on "varaa kapinoida", etsii uusia musiikillisia vaikutteita varsinkin Yhdysvaltain mustasta rhythm and bluesista; sen monet puolet johtavat yhtäältä "sorron" tunnetta korostaviin sivumerkityksiin ja toisaalta suhteellisen luonnonmukaiseen kehonkäyttöön (mikä on potentiaalinen uhka kapitalistiselle työkurille). On huomionarvoista, ettă samankaltaista kapinointia ilmenee suunnilleen samaan aikaan eliittimusiikin alueilla: jazzissa, jossa modernit ja avantgardistiset tyylit sekä hieman toisessa mielessä vanhan jazzin liike ovat haaste swingille, kaupalliselle tanssijazzille sekä mainstreamille; ja konserttimusiikissa, jossa adornolainen kiistely muuntuu kiistaksi toisaalta täydellisen sarjallisuuden ja muiden "järjestelmällisen integralismin" muotojen sekä toisaalta käsitteenä epämääräisen "kriittisen sitoutumattomuuden" välillä. Kuusikymmentäluvun lopulta lähtien esiintyy näiden alueiden samoin kuin myős populaarimusiikin kesken yhä enemmän rajanylityksiä, ja tämä osoittaa konkreettisesti sen kiistämättömän tosiasian, että ainakin sosiaalis-ideologisesta 
ellei nyt aina musiikillis-teknisestä näkökulmasta tarkasteltuna musiikin kenttä on yhtenäinen.

Eittämättă rock and roll ja 60-luvun rockliikkeet puhkesivat kukkaan taustanaan uusi sosiaalihistoriallinen vaihe, nimittäin "hyvinvointikapitalismi" ja lisääntyvă vapaamielisyys. Tämänkaltainen julkinen sallivuus koettiin oikeutetuksi, koska molempina ajankohtina "kapina" oli pääasiassa hegemoniasysteemin osa; se artikuloitui etupäässä vaarattomiin musiikkimuotoihin, joiden piilomerkitykset eivät olleet kovin kumouksellisia (etupäässä oli kyse vapaa-ajan kulutusideologiasta, nuorison varaventtiileistä, romanssihaaveista tähden kanssa jne.). Todelliseen koetukseen tämå ristiriita joutuisi vasta kriittisemmässä taloudellisessa ja sosiaalisessa ilmastossa - mikä oli arvioitavissa punk-rockin käydessä hyökkäykseen sekä vakiintuneita musiikkitottumuksia ja merkityksiä että vakiintunutta tuotantotapaa vastaan. Elämme edelleen punkkauden jälkeisessä taistelutilanteessa.

Tässä esitetyt linjanvedot mainituista kolmesta ajanjaksosta ovat ainoastaan luonnostelmia, ja siten pikemminkin kaavamaisia kuin kuvaavia. Yksi johtopäätös voidaan kuitenkin tehdä: näiden aikakausien tutkimuksen, sen sijaan että se totuttuun tapaan kohdistuisi lajeihin tai henkilöihin tai historiallisiin perinteisiin, tulisi keskittyä musiikillisiin kategorioihin tai elementteihin, jotka artikulaatioprosessin kuluessa kulkeutuvat genrestä genreen, perinteestä perinteeseen ja omaksuvat uusia asemia eri muodoissa ja saavat erilaisia merkityksiä. Esimerkiksi porvarillisen vallankumouksen ajankohtana huomio tulisi kiinnittää kolmeen kategoriaan (porvarilliseen vakiotyyppiin?): neljäneljäsosa-marssiin, symmetriseen, lyyriseen yksinlauluun (joka jakautuu bel cantoksi, kotimusiikiksi ja kansanomaiseksi (volkstümlich) lauluksi; tanssiin (valssi, galoppi jne.). Vastaavat kohteet massakulttuurin kontekstissa voisivat olla pentatoninen melodiikka; ragtimeen pohjautuvat synkopoivat rytmikaavat; myöhäisromanttinen ja impressionistinen laulumelodiikka ja -harmonia. Ja popkulttuurin kohdalla ehkä boogie-tyyliset rytmit (kahdeksan iskua tahdissa); riffirakenteet; antifonaaliset muodot. Vielä muitakin kategorioita voi epäilemättä löytää.

Monimutkaisten, eriytyneiden yhteiskuntien kohdalla on vaarallista ajatella, että musiikkityylit, lajit ja tyypit ovat rakenteiden ja merkityksien tasolla sopusoinnussa keskenään tai että musiikkia ja sen käyttäjiä yhdistäă jokin "ominaisluonne". Edelläolevan perusteella on pikemminkin selvää, että näitä ilmiöitä todennäköisimmin ohjaava periaate liittyy sisäiseen vastakohtaisuuteen. Tämä ei tarkoita, etteivätkö tyylit, lajit ja tyypit saavuttaisi usein näennäistä yhtenäisyyttä, joka voi olla pitkäaikaista, tai että vastakohtaisuus ilmenisi aina samalla tavalla tai samassa laajuudessa: tămä riippuu sosiaalisista tekijöistä, puhumattakaan saatavilla olevan musiikillisen aineiston luonteesta ja määrästä. Mutta nähdäkseni yhtenäisyys on "luonnotonta" - kulttuurisen toiminnan tulosta; musiikilliset yksiköt ovat kooste eri lähteistä peräisin olevista elementeistă, joilla jokaisella on erilaiset historiat ja sivumerkityskasautumat, ja nämä koosteet voidaan sopivissa olosuhteissa jättää merkitykseltäăn avoimiksi, jolloin elementit voidaan artikuloida uudelleen erilaisissa yhteyksissä.

Toisinaan sisäiset ristiriitaisuudet ovat ilmiselviä, kuten silloin kun käytetăăn parodiaa (sanan laajimmassa merkityksessä). (Tämä on suosittu 
tekniikka sorrettujen kansanryhmien muusikoiden parissa.) Joskus ristiriidat ovat melko piileviă, ja niită văhătellăăn kansansivistystyőn, tutunomaistamisen tai Bourdieun mainitseman "legitimaatio"-tekniikan avulla. Ne paljastuvat ainoastaan silloin kun pysyvăt elementit irroitetaan kontekstistaan ja siirretăăn uuteen ympäristöön. Näin esimerkiksi tapahtuu, kun samoja kansanomaisia melodioita, joita 1800-luvun porvaristo suosi lauluissaan (jossa ne tarkoittavat romanttisten käsitysten mukaisesti kansakuntaa ja yhteisőä), käytetään onnettomuuksista kertovissa tyővăenlauluissa; samasta asiasta on kysymys, kun Ray Charles tai Otis Redding "gospelisoivat" tunteellista Tin Pan Alley -melodiaa; tai kun 4/4marssirytmi omaksutaan varhaisen punk-musiikin kritiikin ilmentäjäksi (ks. Laing 1985, 61-63).

Voima, jolla tiettyjă potentiaalisesti ristiriitaisia elementtejă pidetăăn yhdessă riippuu kyseessăolevien artikulointiperiaatteiden voimasta, mikă puolestaan on yhteydessä objektiivisiin sosiaalisiin tekijöihin. John Lennonin Imagine, joka on kuunneltaessa sangen voimakastehoinen, voidaan jälkikäteen hajottaa varsin helposti toisiinsa nähden ristiriitaisiin elementteihin: radikaalit sanat, balladimelodia ja -orkestraatio, laulaja-lauluntekijän ("tunnustuksellinen") pianonkäyttö, soul- ja gospel-sävyinen laulu. Se mikä sitoo nämä yhteen on ihanteellisuus tai konkreettisemmin sanottuna tietty olotila, joka liittyy vieraantuneen älymystőn elämäăn myöhäiskapitalistisessa yhteiskunnassa. Tăllä yllyttävällä (ja vaikuttavalla) "yhtenäisyydellă" ei ole riittåvăsti aineellista tukea (mäărättyjă sosiaalisia intressejä ajatellen) saati ideologista oikeutusta (tai uhkaavuutta), jotta se voisi olla sen enempäă kuin kyseisen musiikkiperinteen henkilökohtainen, väliaikainen suunnanvaihdos (partaradikaalinen ja siten văistyvä). Kun sävelmä soi televisiomainoksen taustamusiikkina - kuten Englannissa tapahtui - se ei juuri katsojaa hätkäytä.

On valaisevaa soveltaa tätä näkökulmaa alkuaikojen rock and rolliin sanokaamme Elvis Presley'in; sillä se mitä tästä musiikista on yleensä kirjoitettu lankeaa juuri siihen ansaan, josta aiemmin varoitettiin. Aluksi rock and roll käsitettiin yleisesti kapinaksi: fanit ja muut suosijat näkivät tämän positiivisena, vallitsevien kulttuuriolojen raivostuneet puolustajat taas negatiivisena. Joka tapauksessa rock oli uutta musiikkia, ja vastakkaista olemassaoleville populaarimusiikin tyyleille.

Sittemmin pitemmälle viety tulkinta historisoi tämän näkemyksen; se kuvasi 50-luvun lopun ja 60-luvun alun populaarimusiikin vaiheet siten, että rock and roll sisällytettiin ja sillä täydennettiin valtaapitävän ryhmittymän ohjelmistoa. Tässä kuitenkin unohtuu ratkaiseva seikka - se että rock and roll oli sisäisesti ristiriitaista alusta lähtien: se ei ollut vain boogie-rytmejä, raakaa sointia, bluesshouteja ja kehonliikkeită, vaan myős tunteellisia laulusävelmiä ja -muotoja, "enkelimäisiä" taustakuoroja ja uutuuskikkoja.

Elviksen tapauksessa tämä ongelma on erityisen silmiinpistävä, koska rockia koskevassa keskustelussa hänet on yleensä nähty sekä tämän musiikin ensimmäisen sankarina että sen huomattavimpana luopiona. Useimmilla rockkriitikoilla on tămä asenne; heidän mielestäăn Elviksen ura oli yltyvää itsensäkauppaamista musiikkiteollisuudelle, siirtymistä kansanomaisesta autenttisuudesta (Sun-yhtiön tuottamat singlet vuosina 1954-55) hienostuneeseen ammattilaisuuteen (1960-luvun hitaat kappaleet ja elokuvat edustivat tätä), jossa 
dollareita tuli monin verroin lisăă, mutta musiikilliset arvot heitettiin syrjään. Greil Marcus on ainoa löytămăni Elvis-kirjoittaja, joka yrittăă vastustaa tătä faustilaista "kăsikirjoitusta", mutta jopa hän, merkatessaan Elviksen urakehityksen taitekohtaa, sijoittaa sen kultaisen Sun-kauden "vapauden tilan" ja myöhemmän rappion văliin, jolloin Elvis turvautui "riskittömăän siloestetiikkaan" ja "tarjosi yleisölleen kaikenkattavia myönnytyksiä" (Marcus 1977, $141,166,199)$.

Mutta sodan jälkeen Yhdysvalloissa puhdas kansanlaulajatyyppi, jota kaupallisuus ei olisi koskettanut, oli mahdottomuus. Radion ja äänilevyn välittämä musiikki tavoitti koko maan ja jokaisen sosiaalisen kerrostuman. Nuoren Elviksen esikuvat - gospel- ja blueslaulajat kuten Arthur Crudup, Bill Broonzy, Junior Parker ja Howlin' Wolf, country \& western -tähdet kuten Bob Wills, Hank Williams ja Roy Acuff - olivat kaupallisia artisteja; heille niin kuin Elvikselle itselleenkin kelpasi kaikki käytettävissä oleva musiikillinen aines. Kun Sun-yhtiön perustaja ja Elvis Presleyn "luoja" Sam Phillips lausui "jos voisin löytää valkoihoisen, jolla olisi neekerin ääni ja neekerin olemus, voisin ansaita miljardi dollaria" (lainaus, Hopkins 1971, 66), hän ei tehnyt eroa taiteellisen ja kaupallisen välillä, eikä näitä motiiveja voida erotella. Jos katsomme musiikkia, jota Elvis teki uransa aikana, on siinä liian monia seikkoja, jotka sotivat "rappio ja tuho"-näkemystă vastaan. Kriitikot painottavat usein liikaa Elviksen "soundinmuutosta" (esimerkiksi "primitiivisistä" - ja siten "autenttisista" Sun-kauden äänityksistä RCA:n "kehittyneisiin" - ja siten "manipuloiviin" menetelmiin, joissa vahvistimien, taustalaulun ja jousien käyttö on pitemmälle vietyä); tämän he katsovat tapahtuneen sellaisten musiikkityylin ominaisuuksien kustannuksella, jotka korostavat jatkuvuutta.

Elviksen kaksi tärkeintä vaikutusta rock and rollin kieleen ovat ensinnäkin "romanttisen lyyrisyyden" käyttő sekä toiseksi tyylikeino, jota kutsun "boogittamiseksi". Molemmat tekniikat ovat klassisessa muodossaan hänen ensimmäisessä kansallisessa hitissään "Heartbreak Hotel" (1956). Se oli alkuaan kantrikappale, mutta melodiahahmoltaan se on tyypillinen blues shout. Kuitenkin karhea ääni, epäsäännölliset rytmit ja "likainen" intonaatio, joita useimmat blueslaulajat olisivat tässä käyttäneet, loistavat lähes poissaolollaan Elviksen esityksessä; hänen äänensä on täyteläinen, sävykäs ja soiva, hänen intonaationsa on tarkka, vakaa ja "oikeaoppinen", sävelet soivat pitkään, ovat kestoltaan venytettyjä, ja fraseeraus on legatossa.

Toisaalta tätä lyyristä jatkuvuutta katkotaan boogittamisen avulla. Kuten

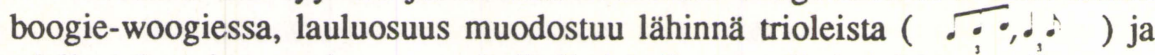
edelleen boogie-woogien tapaan heikolle iskulle osuvalle kahdeksasosalle sattuu usein odottamaton aksentti, josta syntyy synkopointia ja polyrytmiikkaa. Vaikutus on fyysinen; se vaatii liikettä, se saa lantion keikkumaan. Elvis kuitenkin laajentaa tätä tekniikkaa. Hän lisää ylimääräisiä synkopoivia säveliä, joita sanat tai melodia eivät välttämättä kaipaa, ja tämä tapahtuu usein erottamalla vokaaleita tai konsonantteja toisistaan, sitomalla sanoja yhteen ja hämärtämällä niiden merkityksiä. 
sekä
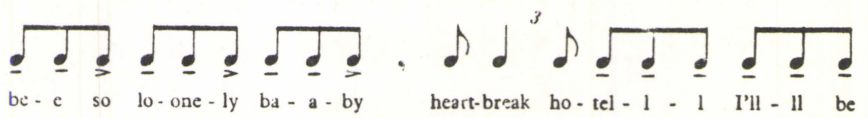

sekä
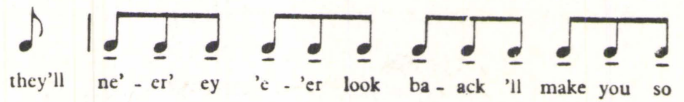

Toisinaan csiintyy pitkään soiva sävel, joka kuulostaa lähinnä rytmiseltä vibraatolta (triolirytmissä): esimerkiksi sanan "Although" kohdalla toisen ja viimeisen säkeistön alussa, sanan "Now" kohdalla kolmannen ja sanan 'Well" kohdalla neljännen säkeistön alussa. Boogittamistekniikan yleisvaikutus on tietenkin sukupuolisesti kiihoittava, mutta se on myös hieman hermostunut ja absurdi; aistillisuus tuntuu lähes riistäytyvän pidäkkeistään. Boogittamisen ja romanttisen lyyrisyyden yhdistelmä "Heartbreak Hotelissa" - toisen elementin ollessa peräisin Tin Pan Alley -laulujen haaveellisuudesta, toisen Yhdysvaltain mustien alakulttuurista, molemmat täydellisesti yhdistyneinä tai pikemminkin keskenään jännitteisinä - synnyttää erityisen tyylin. Se hipoi jo Elviksen uran varhaisvaiheessa sitä melodramaattisuutta, johon hän sittemmin niin usein lankesi. Näiden kahden elementin artikuloituminen yhteen uuden nuorisokulttuurin asettamissa puitteissa ja kontekstissa kuvastaa tămän musiikinhistorian vaiheen yleistä problematiikkaa; yleisesti ottaen voimme ajatella romanttista haavekuvaa, joka on nuori, lihaa ja verta ja joka saa kuulijan kehon liikkeeseen, mutta jossa ruumiillinen vapaus esitetään käănteisesti, samassa hengessä kuin suhtautuminen aikuisten seksuaalisuuteen protestanttisessa porvarillisessa yhteiskunnassa, eli săădeltynă, personoituna ja jopa ironisoituna.

Sama tekniikkojen yhteensulautuminen on nähtävissä jopa aiemmin, kun Elvis oli vielä Sun-yhtiön leivissă. "Milkcow Blues Boogie" (1955) on tåstä kenties paras esimerkki. Tekniikat ovat taas erittäin hyvin integroituneet, vaikka Elvis esittääkin laulun niin nopeassa tempossa, ettă itse tekniikkojen käyttő ei tule niin selvăsti esille kuin "Heartbreak Hotelissa". Lyyrinen puoli - săvykäs äăni, liu'ut sävelen ohi, pitkäänsoiva legato, tarkat säkeiden loput - näkyy selvimmin kunkin săkeistőn lopussa. Boogittaminen hallitsee koko lauluosuutta, vaikka nopean tempon vuoksi synkopoinnille on văhemmăn tilaa, ja usein efekti on niin nopea ettå se kuulostaa rytmiseltå vibraatolta. Tempo tekee myðs tarkan nuotinnoksen vaikeaksi. Joka tapauksessa alussa kuulemme jotakin tämänkaltaista:

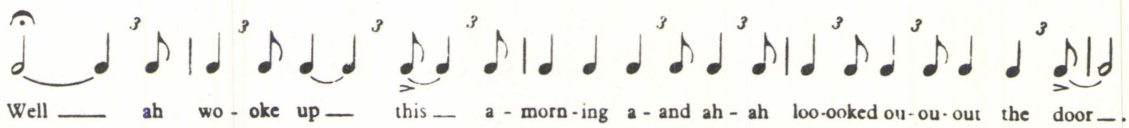

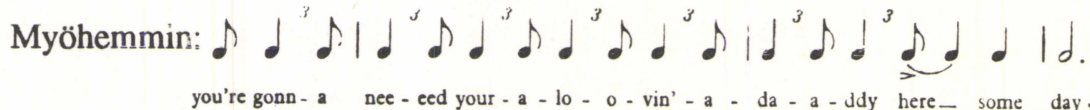

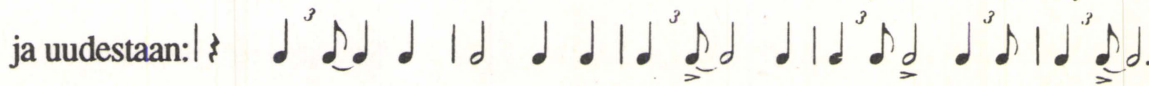

Well - Il_ ah tried ev'-ry thi-ing_ to git a-long with-a you-ou_. 
Romanttinen lyyrisyys ja boogittaminen eivăt esiinny ainoastaan Elviksen uran alussa, vaan niiden kăyttő jatkui myős koko urakehityksen ajan. Mităăn vedenjakajaa tai "tyylinmuutoksen hetkeä" ei ole. Sen sijaan jonkinlaista tyylillistä erikoistumista on kyllä havaittavissa. Laulut, joissa năitä kahta tekniikkaa yhdistellään, kuten "Milkcow Blues Boogie" (tai "Mystery Train") Sun-yhtiön kaudelta tai "Heartbreak Hotel" varhaiselta Victor-levyjen kaudelta tulevat harvinaisemmiksi. Tekniikat pyrkivät irtautumaan toisistaan, jolloin romanttinen lyyrisyys kanavoituu hitaisiin lauluihin, boogittaminen taas tietynlaisiin rock and roll -kappaleisiin, joita kutsun "manieristisiksi". Elviksen valtavaan balladiohjelmistoon ei tässä tarvitse juuri puuttua, paitsi jălleen painottamalla, ettei se alkanut RCA-yhtiöön siirtymisen yhteydessä, vaan Sunkaudella. "Love Me Tenderiä" (1956) ja "That's When Your Heartaches Beginiă" (1957) edelsivät yhtä tunteelliset laulut, jotka Elvis levytti Sam Phillipsille. Hitaiden laulujen aika alkoi todellakin aiemmin: kun Elvis poikasena osallistui kykyjenetsintäkilpailuihin Mississippi-Alabama -messuilla, hăn lauloi juuri balladin "Old Shep".

"Maneeri-rock" on kiinnostavampaa. Se liittyy selvimmin joukkoon lauluja, joista monet olivat Otis Blackwellin Elvistä varten tekemiă; sarja alkoi kappaleilla "Don't Be Cruel" (1956) ja "All Shook Up" (1957) ja ulottui lauluun "Please Don't Drag that String Around" (1963). Boogittamistekniikka on liioitellusti esillä, sitä ylikorostetaan, jopa parodioidaan. Turvautumalla manierismiin, ylikorostukseen Elvis etäännyttäă itsensä tekniikan sekä fyysisistă ettă psykologisista vaatimuksista. Esimerkiksi kappaleessa "All Shook Up" käytetään vanhoja tekniikkoja:

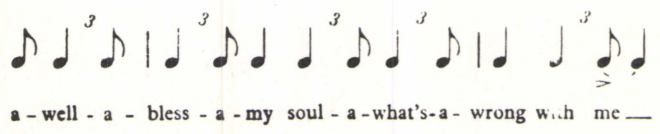

Mutta laulun sanojen triviaalisuus ja Elviksen kevyt, huvittunut ăni kertovat, ettei laulaja ole vakavissaan. Manierismia on tavallisesti pidetty RCA-vaiheen kehitykseen kuuluvana; mutta taas kerran huomataan, ettă se syntyi jo Sunkauden aikana, erityisesti kappaleessa "Baby Let's Play House" (1955).

Artikulointisuhteissa on selvästi tietty määră "löysyyttä", siis sitä ettă tekniikkojen yhdistăminen ei liitä mităăn musiikillista yksikkőă sataprosenttisesti johonkin toiseen, ja juuri tămä selittää sen ettă keitoksen eri elementit ovat kehittyneet eri tahtiin ja eri suuntiin - jolloin kyseessä eivät ole "tyylinvaihdokset".

Elviksen merkitys ei siten ole niinkään silloisessa abstraktissa tyyliele menttien sekoituksessa (blues/country/Tin Pan Alley), jonka hän toi rock and rolliin, vaan siinä, miten hän näită elementtejä sekoitteli. Hän muunsi ne artikuloi ne - tietyiksi kaavoiksi. Elviksen musiikkia ei siis voi luokitella, kuten olemme havainneet, historiallisten kausien mukaan vaan laulutyyppien mukaan tai tarkemmin sanottuna näennäisesti ristiriitaisten musiikkielementtien yhdistelmien mukaan, siten kuin ne välittyvät eri hetkinä eri laulujen erilaisia vaatimuksia noudattamaan. Ajan kuluessa ne laulut, joissa tyylielementit 
muodostavat integroituneen kokonaisuuden, käyvät vähitellen harvinaisemmiksi Elviksen uralla. Vastaavasti laulutyypit pyrkivăt eriytymään samassa tahdissa kuin Sun-kauden suhteellisen pieni ja tarkasti rajattu yleisö korvautuu suurilla heterogeenisilla markkinoilla, jossa eri alaryhmät vaativat erilaisia laulutyyppejă.

Elvis on tätä kaikkea yleisőlleen läpi koko uransa, mutta yleisön luonne muuttuu, ja yleisön mukana muuttuu myös musiikkimateriaalin artikulointien luonne ja ala. Yhdistävä tekijä on Elvis itse - tai paremminkin Elvis sellaisena kuin eri luokat hänet näkevät, sellaisena miksi eri artikulointitekijät hänet muovaavat, sellaisena joksi tietyt sosiaalisten tarpeiden ja intressien kokoelmat hänet vangitsevat. Nämä kokoelmat - ja kaikkein silmiinpistävimpiä ovat rock and rollin syntykauden tekijät - liittyvät erilaisiin sosiaalisiin konteksteihin. Ottaen huomioon musiikillisen joukkotuotannon vaateet tuo ajankohta, tuo sosiaalisten intressien kokoelma tarvitsi Elvistä, tarvitsi tähteä, jotta olisi voinut asettaa kyseenalaiseksi senhetkisen kulttuurisen ylivallan; mutta samalla tämä tähti oli noiden objektiivisten sosiaalisten intressien tuote - ja hänetkin voitiin artikuloida uudelleen, hänen imagoansa ja niin muodoin hänen esitystään voitiin työstää ja tulkita uudelleen miellyttämään erilaisia yleisöjä.

Ellei meillä olisi käytőssä tämänkaltaista analyyttista viitekehystä, joka ottaa huomioon siirtymävaiheen moninaiset tasot ja niiden suhteellisen autonomian, Elviksestä tulee puhdas poliittisten voimien väline (kapinoiva ja manipuloitavissa oleva); monet seikat jäävät edelleen hämäriksi: esimerkiksi se että nuori rokkari lauloi hitaita kappaleita alusta asti, että vanha Hollywood-tähti kykeni yhä laulamaan rock and rollia ja että rockfanit yhä kunnioittivat häntä, että hänen blues-laulunsa olivat yhä "romanttisia" (eräänlaista fantasiaa), hänen balladinsa usein "realistisia" (lihaa ja verta) tai että hän kykeni tekemään boogittamisesta ironiaa.

Elviksen ja varhaisen rock'n'rollin tarjoama esimerkki on tietenkin erikoistapaus, koska se on sidoksissa tiettyyn erikoislaatuiseen ajankohtaan, jolle näyttää olleen luonteenomaista melko syvä muutostila. Toisentyyppiset ajankohdat edellyttäisivät hieman erilaisen näkökulman soveltamista ja antaisivat erilaisia tuloksia.

\section{Huomautus}

Pidempi versio tästä artikkelista on Middleton 1984/5 sekä Middleton 1985A. Osia tästä on ilmestynyt myös Middleton 1979, Middleton 1982 ja Middleton 1985B. Näistä viimeisessä on pitempi selostus artikkelin pohjana olevasta teoreettisesta viitekehyksestä. 


\section{Lähteet}

Chambers, Iain

1982 "Some critical tracks". - Popular Music 2, 19-36.

Fabbri, Franco

1982 "Musical genres and their metalanguages", paper delivered to the ISME conference, Pop and Folk Music: Stocktaking of New Trends, Trento 1982.

Gramsci, Antonio

1971 Selections from the Prison Notebooks, ed. Quintin Hoare and Geoffrey Nowell-Smith. London: Laurence and Wishart.

Hall, Stuart

1981 "Notes on deconstructing 'the popular'". - People's History and Socialist

Hebdige, Dick

Theory, ed. Raphael Samuel, 227- 240. London: Routledge.

1979 Subculture: the Meaning of Style. London: Methuen.

Hopkins, Jerry

1971 Elvis: a Biography. New York: Simon and Schuster.

Laing, Dave

1985 One Chord Wonders. Power and meaning in Punk Rock. Milton Keynes.

Marcus, Greil

1977 Elvis: Presliad. - Mystery Train. London: Omnibus Press.

Marothy, Janos

1974 Music and the Bourgeois, Music and the Proletarian. Budapest: Akademiai Kiado.

Mercer, Colin

1978 "Culture and ideology in Gramsci." - Red Letters 8, 19- 40.

Middleton, Richard

1979 "All shook up: continuity and change in Elvis Presley's vocal style." Elvis: Images and Fancies, ed. Jac. L. Tharpe, 151-161.Jackson, Miss.: University Press of Mississippi; reprinted London: W.H. Allen 1983. (with John Muncie)

1982 Pop Culture, Pop Music and post-War Youth: Countercultures. Open University course U203, Popular Culture, Unit 20. Milton Keynes: Open University Press.

1984/5: "Articolare il significato musicale" - Ricostruire una storia della musica - Collocare il popolare. - Musica/Realta, 15-16, 63-84, 97-118.

1985A "Articulating musical meaning/re-constructing musical history/locating the popular." - Popular Music 5, 5-43.

1985B "Popular music, class conflict and the music-historical field:" Popular music perspectives 2, ed. D. Horn. Göteborg/Exeter/Ottawa/Reggio Emilia.

Mouffe, Chantal

1979 "Hegemony and ideology in Gramsci." - Gramsci and Marxist Theory,

Wicke, Peter chapter 5. London: Routledge.

1982 "Rock music: a musical-aesthetic study." - Popular Music 2, 219-243. Willis, Paul

1978 Profane Culture. London: Routledge. 
Articulating musical meaning / re-constructing musical history / locating the "popular"

The main purpose of this article is to discuss how popular music and its meanings can be located in music history. One possible way is to locate musical categories topographically. The key terms here are "process", "relationship", "transformation", "contradiction". What the term popular music tries to do is to put a finger on that space of contradiction - between elite and common, predominant and subordinate, then and now etc., - and to organise it in particular ways. These relationships must be analysed in different contexts, and the possible meanings of popular music must be historically located, too.

Another way of approaching this area is in terms of the relative autonomy of cultural practices. According to this Gramscian view cultural relationships and cultural change are not predeterminated; rather, they are the product of negotiation, imposition, resistance, transformation, etc. The "principle of articulation" helps us to understand how musical elements, forms and types are appropriated for use by particular classes or groups of classes. The argument is that while elements of culture are not directly tied to specific economically determined factors such as class position, they are determinated in the final instance by such factors, through the operation of articulating principles (sets of values) which are tied to these factors. These principles operate by combining existing elements into new patterns or by attaching new connotations to them.

However, the theory of articulation does not mean that the musical field is a pluralistic free-for-all. It is not undeterminated, but overdeterminated, and the ruling interests in the social formation take the lead in setting the predispositions which are always trying to constitute a received shape. This would-be universalising push of the ruling class provides one of the most important elements in music history over the last two hundred years.

In sketching out this music history, one can identify three "moments" of radical change. It is on these moments that, at the present stage of knowledge, research should be concentrated, since they reveal most clearly the processes of formation of a musical-ideological field. First is the moment of the "bourgeois revolution". In most European countries this period would appear to begin in the late eighteenth century and to give way a more stable period after the 1848 revolutions. Conventional music history of this period contains a complex web of interactions - involving concert music, middle-class domestic genres, theatre music, dance, the mass choral movement, and political and protest songs - which were the object of active struggle, as old and new elements were articulated into a variety of patterns and meanings.

The second moment is that of "mass culture", running from the late nineteenth century to around 1930. It is characterised by the development of monopoly-capitalist relations and dichotomous class forms. National cultures are counterbalanced by a growing internationalisation, associated particularly with an emerging American hegemony. This shows itself both in musical content - the 
impact of ragtime, jazz, Tin Pan Alley songs, new dance forms, etc. - and in new methods of mass production.

The third moment begins sometime after the Second World War, and can perhaps be termed the moment of "pop culture". In this period changes in technology create a potential for new production methods, and there are accompanying changes in relations of production, most importantly, the first significant encroachment on music production resources by young amateurs, together with the opening up of a new market, that of "youth", which is structurally less tied to established class roles than older generations.

Research into these periods should concentrate on musical categories or elements which, within the articulative process, migrate from genre to genre, tradition to tradition, assuming new positions in different patterns, taking on varied meanings. It is clear that the principle most likely to govern these phenomena has to do with internal contradiction. It is instructive to apply this perspective to early rock and roll, e.g. Elvis Presley, for his music was internally contradictory from the start. Elvis's two most notable contributions to the language of rock and roll were the assimilation of "romantic lyricism" and "boogification". The importance of Elvis lies not so much in the abstract mix of elements (blues/country/Tin Pan Alley), which he helped to bring into being in rock and roll, but in what he did with it. He transformed them - articulated them into particular patterns. The only workable categorisation of Elvis's music is not by historical period but by apparently selfcontradictory assemblages of musical elements as they are mediated by the differential demands of varied songs at various moments. What does happen historically is that integrated songs become gradually less common through the course of Elvis's career, while the song-types tend to diverge, as the relatively small, well-defined audience gives way to a large, heterogenous market demanding different types for different sub-sections. 